\title{
by Bruno Cagnoli
}

\section{Fuzzy logic in volcanology}

\author{
Department of Earth and Ocean Sciences, University of British Columbia, 6339 Stores Road, Vancouver, B. C., Canada V6T 1 Z4
}

\begin{abstract}
Fuzzy logic is probably a simple and powerful tool to model volcanic systems because it enables a mathematical formalization of ill defined problems and geological knowledge is typically imprecisely defined. Fuzzy logic enables more flexible classifications because it deals with sets whose members belong to them to only some degree. There are a lot of examples of geological objects that do not fit well into traditional classifications because they have their own characteristics to only some degree, such as rock properties. The aim of this short note is to bring the fuzzy logic philosophy to a broad audience with the hope that it will become more popular among geologists.
\end{abstract}

\section{Introduction}

The need to classify objects which do not fit well in a given scheme is a frustrating experience quite common in geology because a lot of geological entities have their own particular features to only some degree. Rocks are a common example of vagueness, they show an internal, infinite variety of fabrics, textures and mineralogical compositions in a continuous spectrum with few well defined breaks (Best, 1982) and usually they do not fit well into a single category because show mixed features (MacKenzie, Donaldson and Guilford, 1987). We use expressions like "texture with ophitic tendency" or "sub-idiomorphic phenocrysts", because these rocks are ophitic and the phenocrysts are idiomorphic to only some degree. We can also say for example that a rock is porphyritic-aphanitic (Best, 1982) when it has at the same time these two opposite characteristics: presence and absence of visible crystals.

A less obvious example of fuzziness is the concept of temperature of a lava flow. This property cannot be described with a single value, because portions of the flow can be below the solidus temperature, others well above it and others with intermediate values. For this reason Rothery and Pieri (1993) wrote: "the measurements of physical properties of lava flows can be elusive not only in their exe-
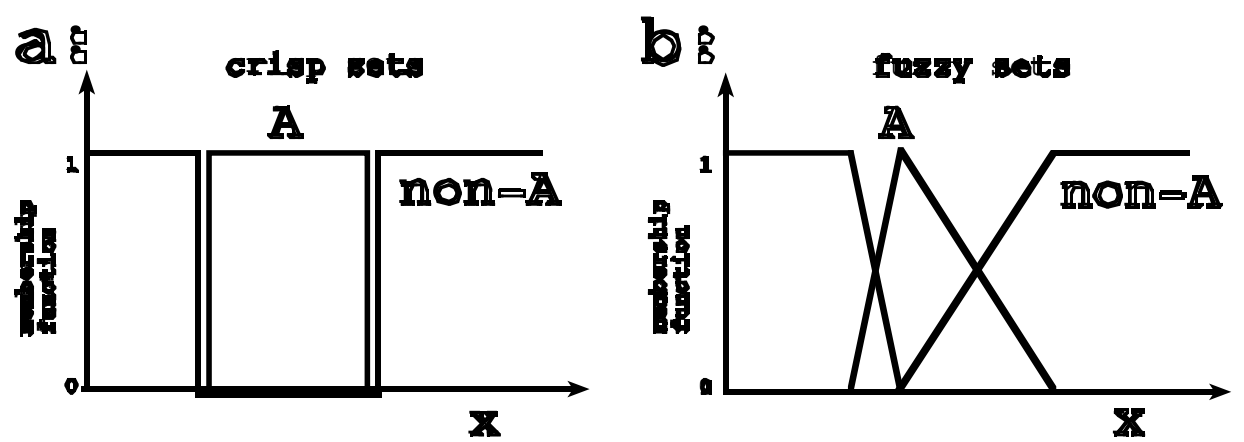

Figure 1 (a): the union of a crisp set $A$ and its complement non-A is the set of all the elements of the universe, while their intersection is the null set. (b): this is not valid for fuzzy sets because they overlap (after Ross, 1993). cution but also in their meaning". So a lava flow can have at the same time an high temperature and a low temperature. Another example of fuzziness is the transport mechanism of a moving pyroclastic flow, which can be laminar and/or plug flows but with turbulence becoming probably important when the flow is significantly violent (Cas and Wright, 1988), but laminar and turbulent flows are opposite end-members. Similarly a sedimentary gravity flow can be a combination of grain flows, debris flows and turbidity currents and its nature is probably changing in time and space (Middleton and Hampton, 1973). The reader is certainly able to imagine a lot of other examples of fuzziness in geology, with properties and their opposites present at the same time but in varying degrees. The aim of this note is to suggest that volcanology is a field where fuzzy logic can be widely applied because vagueness is probably a natural feature of the real world and that fuzzy logic can be particularly useful to describe geological systems in a relatively easy way.

\section{Fuzzy logic}

Professor Lofti Zadeh (1965) of the University of California at Berkeley is the father of fuzzy logic. He suggested that to study natural systems a mathematics of fuzzy and cloudy quantities was needed. Fuzzy logic deals with fuzzy sets, whose characteristic is to have elements belonging to them only to some degree according to a membership function with values between 0 and 1 . For example a square drawn by hand belongs partially to the set of squares (that are pure mathematical ideas) and partially to the set of non-squares because it cannot be perfect. So a fuzzy set (A) and its complement (non-A) overlaps, because some elements can belong to both. To realize the differences between classical and fuzzy logic it is worthwhile to note that the so called Excluded-Middle laws $(\mathrm{A} \cap$ non- $\mathrm{A}=$ $\varnothing$ and $A \cup$ non- $A=X$, where $\varnothing$ is the null set and $X$ is the set of all the elements of the universe), that hold for classical logic, do not hold for fuzzy logic where $A \cap$ non- $A \neq \varnothing$ and $A \cup$ non- $A \neq X$ (Ross, 1993). This is shown in Figure 1 where fuzzy sets have been drawn using their membership functions. For this reason fuzzy logic admits contradictions, because one object can be at the same time partially A and partially non-A. Common membership functions are triangles, trapezoid and even Gaussian, bell-shaped curves.

A so called fuzzy rule relates fuzzy sets using conditional IFTHEN sentences like "IF Y is A THEN Z is B" where A and B are fuzzy sets. A fuzzy system is a set of fuzzy rules connecting fuzzy input and fuzzy output in the form of IFTHEN sentences (Jamshidi, Vadiee and Ross, 1993). For this reason a fuzzy system represents a particular knowledge or expert system. A trivial example could be: 1) if it is hot, turn down the heater, 2) if it is cold, turn up the heater, etc., where hot, cold, turn-down, turn-up are all concepts that can be represented by fuzzy sets. In such systems, more than one rule can fire at the same time and in parallel. A useful, but non academic introduction to fuzzy 
logic is Kosko (1994), it has the advantage to let the beginner skip the formalism of the technical books and understand the philosophy of fuzzy logic. Another brief introductory paper is Fang (1997) where two examples of applications of fuzzy logic to stratigraphy and porosity are mentioned.

\section{Fuzzy sets in volcanology}

In this paragraph I would like to show a simple case where the use of fuzzy sets with their membership functions would create a better classification. For example, regarding sorting, a pyroclastic deposit can be (Cas and Wright, 1988): 1) very well sorted $\left.\left(\sigma_{\phi}=0-1\right) ; 2\right)$ well sorted $\left.\left(\sigma_{\phi}=1-2\right) ; 3\right)$ poorly sorted $\left.\left(\sigma_{\phi}=2-4\right) ; 3\right)$ very poorly sorted $\left(\sigma_{\phi}>4\right)$. These four sets are classical, crisp sets whose elements belong to them $100 \%$ yes or $100 \%$ no, without intermediate possibilities. This seems logical but in reality strange situations occur. For example, is a deposit with $\sigma_{\phi}=2$ well sorted or is it poorly sorted ? Is a rock with $\sigma_{\phi}=1.1$ as well sorted as one with $\sigma_{\phi}=1.5$ ?

A much smarter descriptive classification would be possible with fuzzy sets, even using just simple triangular membership func- tions (Figure 2), although the shape and size of the membership functions need to be fixed experimentally. In this case a sample with $\sigma_{\phi}=2$ would have intermediate values between 1 and 0 of the membership functions in both the "well sorted" and "poorly sorted" fuzzy sets, quantifying in such a way its intermediate characteristics (Figure 2). Similarly a sample with $\sigma_{\phi}=1.1$ close to the boundary of the set and a sample with $\sigma_{\phi}=1.5$ located in the center of the set would have different values of the membership function. This is just a simple example showing how fuzzy sets can improve the quality of the description of the natural world representing its vagueness in an easy way. In this case a sample with $\sigma_{\phi}=2$ would be at the same time well sorted and poorly sorted but to different degrees, and this is not a contradiction in fuzzy logic.

\section{Fuzzy systems in volcanology}

The table (Figure 3) with the criteria for the volcanic explosivity index (VEI) published in Fisher and Schmincke (1984), but after Newhall and Self (1982), can be easily transformed into a fuzzy system. In this case the volumes of ejecta, column heights, durations (hours of continuous blast), tropospheric and stratospheric injections can be considered as the input fuzzy sets (whose values A:
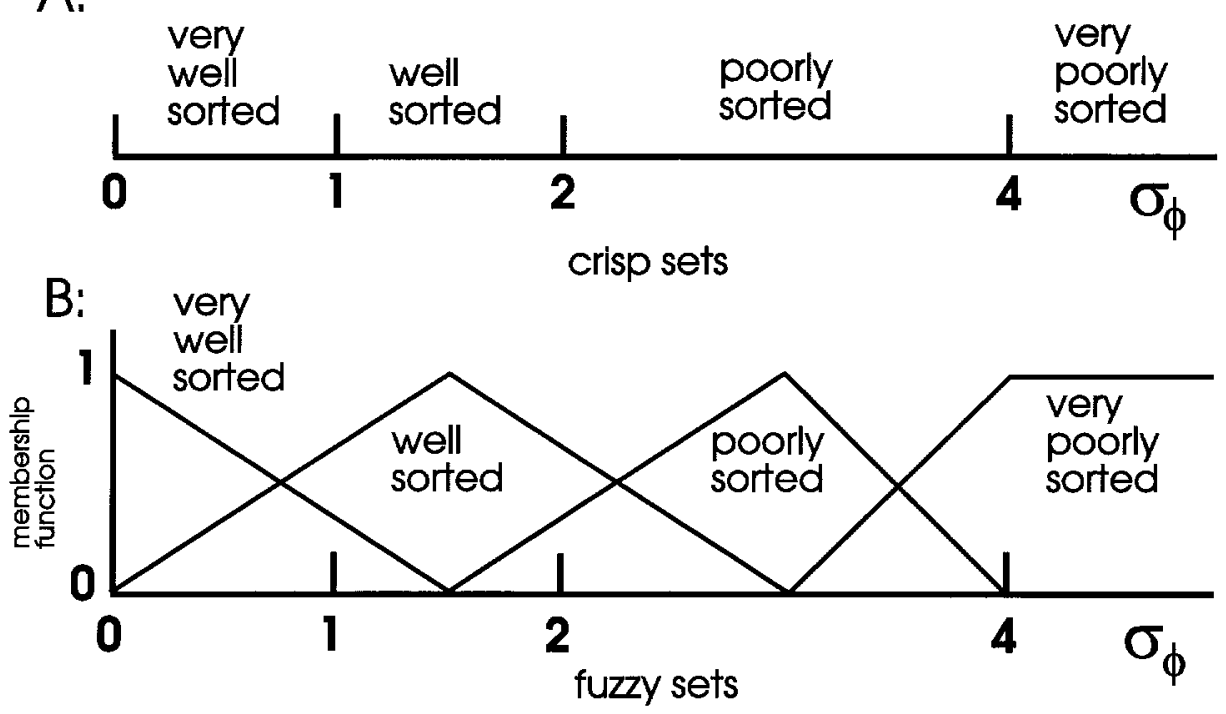

Figure 2 A: sorting of a pyroclastic deposit with crisp sets (Cas and Wright, 1988). B: sorting using fuzzy sets. The shapes and sizes of the membership functions are arbitrary and used only as an example to show the philosophy of fuzzy logic. can be measured in the field) while the classification of the volcanic activities (Hawaiian, Strombolian, Vulcanian, Plinian and Ultraplinian) can be considered as the output fuzzy sets. Figure 4 shows a portion of this table that is relatively easy to rewrite using fuzzy sets. Of course triangular membership functions are arbitrary, and again their shape and size can be improved using observations, deductions and experiments. This approach is needed to transform into fuzzy sets also the other input variables of Figure 3. The fuzzy rules connecting inputs to outputs in this system are represented by the graphical, vertical correspondence between sets in the table of Figure 3 and are equivalent to IF-THEN sentences. In this very simple system IF the volume of ejecta, column height, duration, tropospheric and stratospheric injection of a certain eruption are small, negligible, none, etc., THEN the activity is for example Hawaiian. Fuzzy systems could be used to relate causes and effects in extremely complex volcanological systems (that mathematics is unable

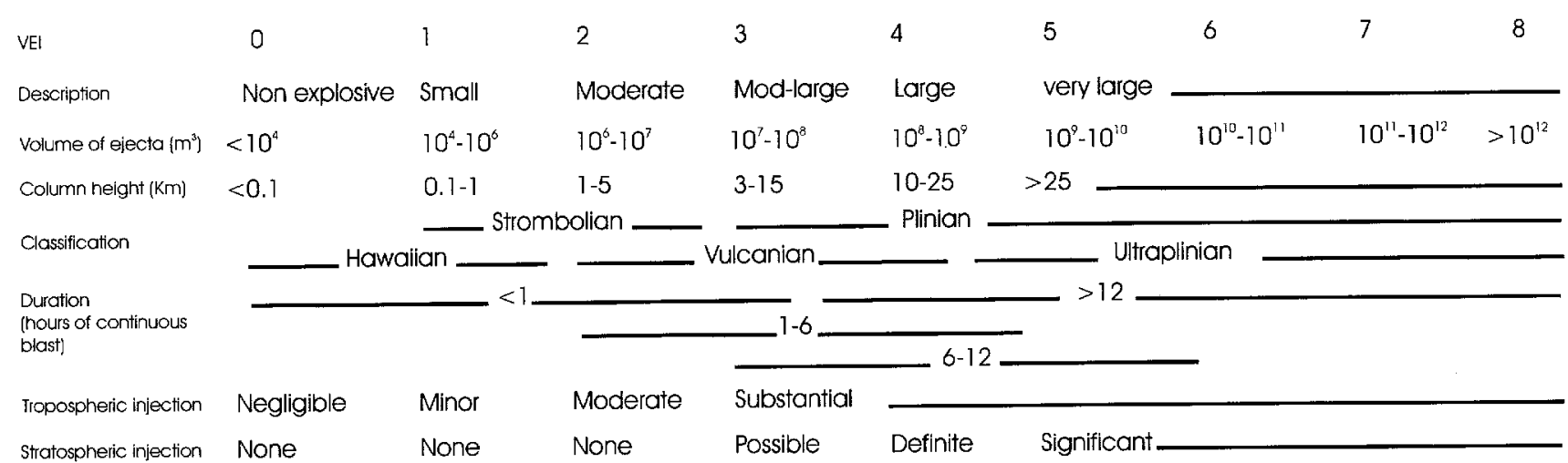




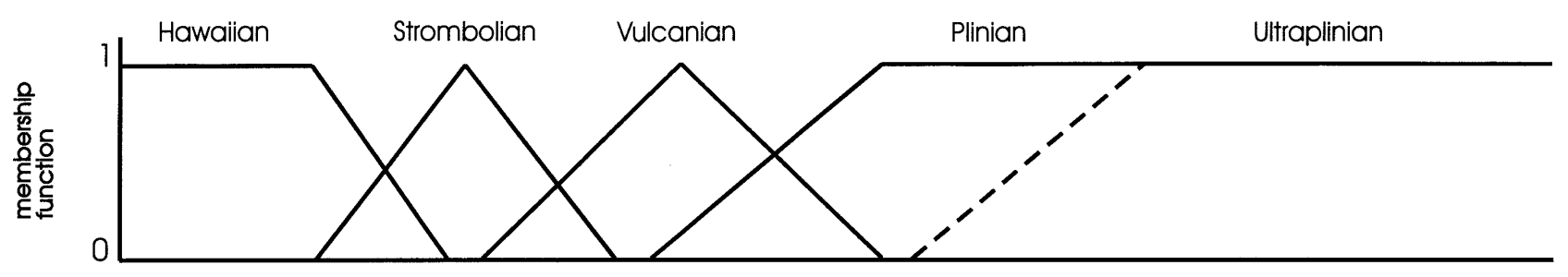

Classification

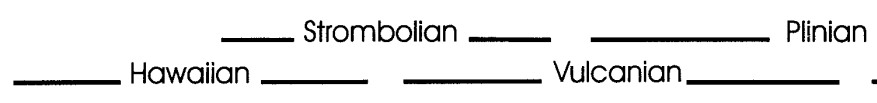
Ultraplinian

\section{input fuzzy sets:}

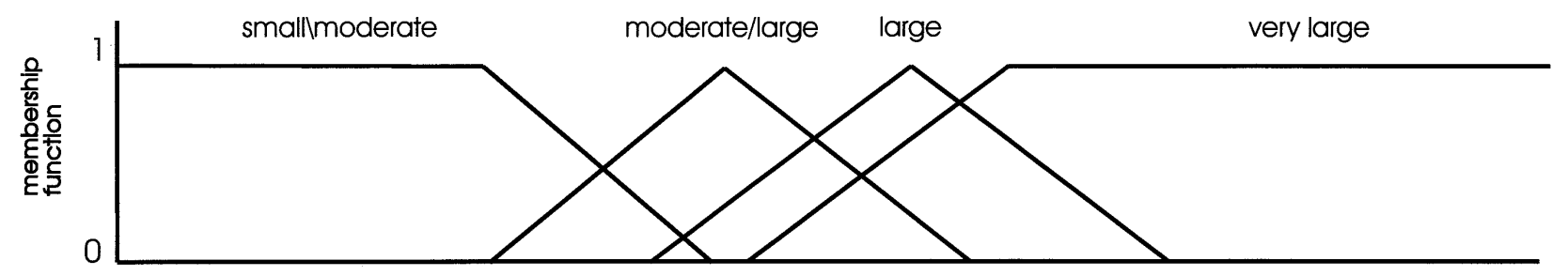

Duration

(hours of continuous

$<1$

blast)

$1-6$ $>12$

\section{Figure 4 One of the inputs and the output fuzzy sets obtained from Figure 3. Again the shapes of the membership functions are} arbitrary and used only as an example.

to handle) using experiments to assess membership functions, fuzzy rules, fuzzy sets, etc. Then to obtain just a single answer some (defuzzyfication) technique of the output fuzzy sets is required (Jamshidi, Vadiee, and Ross, 1993).

\section{Conclusions}

A good question could be: why is it so difficult to model complex volcanological systems ? Is this due to lack of knowledge or to the fact that classical logic is too rigid while nature is fuzzy and vague ? The occurrence in geology of a lot of exceptions and intermediate characteristics suggests that a rigorous, classical logic is inadequate to describe the real world. On the contrary, fuzzy logic is a mathematical tool useful to model non-well defined system in a relatively easy way. In any case, it is important to emphasize that there is a conceptual difference between fuzzy logic and probability theory (in spite of the fact that a Gaussian curve can be used as the membership function of a fuzzy set) because while the former is able to suggest a logic upon which nature works, the latter is interested in the most frequent occurrences.

\section{References}

Best, M.G., 1982, Igneous and metamorphic petrology: W.H. Freeman and Company, San Francisco, 630 pp.

Cas, R.A.F., and Wright, J.V., 1988, Volcanic successions, modern and ancient: Chapman and Hall, London, 528 pp.

Fang, J.H., 1997, Fuzzy Logic and Geology: Geotimes, 42, 10, pp. 23-26.

Fisher, R.V., and Schmincke, H.-U., 1984, Pyroclastic rocks: Springer-Verlag, Berlin, $472 \mathrm{pp}$.

Jamshidi, M., Vadiee, N., and Ross, T.J., 1993, Fuzzy logic and control, software and hardware applications: Prentice Hall, Englewood Cliffs, 397 pp.

Kosko, B., 1994, Fuzzy thinking: Flamingo, London, 318 pp.
MacKenzie, W.S., Donaldson, C.H., and Guilford, C., 1987, Atlas of igneous rocks and their textures: Longman Scientific and Technical, London, 148 pp.

Middleton, G.V., and Hampton, M.A., 1973, Sediment gravity flows: mechanics of flow and deposition, in Middleton, G.V., and Bouma, A.H., eds, Turbidites and deep water sedimentation, vol. 1, S.E.P.M. Short Course, pp. 1-38.

Newhall, C.G., and Self, S., 1982, The volcanic explosivity index (VEI): an estimate of explosive magnitude for historical volcanism: Journal of Geophysical Research, v. 87, pp. 1231-1238.

Ross, T.J., 1993, Set theory - Classical and fuzzy sets, in Jamshidi, M., Vadiee, N., and Ross, T.J., eds, Fuzzy logic and control, software and hardware applications: Prentice Hall, Englewood Cliffs, pp. 10-35.

Rothery, D.A., and Pieri, D.C., 1993, Remote sensing of active lava, in Kilburn, C.R.J., and Luongo, G., Active lavas: UCL Press Limited, London, $374 \mathrm{pp}$.

Zadeh, L.A., 1965, Fuzzy sets: Information and control, v. 8, pp. 335-353.

Bruno Cagnoli obtained a Degree in Geology at Bologna University (Italy) and an M.phil at Plymouth University (UK) under the supervision of Prof. D. H. Tarling. His research interests are devoted to volcanology and in particular to pyroclastic flow and base surge deposits. He is currently working for a PhD at the Department of Earth and Ocean Sciences of the University of British Columbia, Vancouver, Canada.

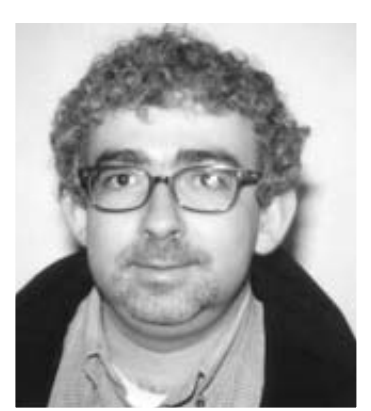

